\title{
Be Your Best You: An Evaluation of a Positive Psychology Intervention Programme in Greece
}

\author{
Aikaterini Kotsoni, Antigoni Mertika, Anastasios Stalikas \\ Department of Psychology, Panteion University of Social and Political Sciences, Athens, Greece \\ Email: kotsonikaterina@gmail.com
}

How to cite this paper: Kotsoni, A., Mertika, A., \& Stalikas, A. (2020). Be Your Best You: An Evaluation of a Positive Psychology Intervention Programme in Greece. Psychology, 11, 1021-1036.

https://doi.org/10.4236/psych.2020.117067

Received: June 22, 2020

Accepted: July 24, 2020

Published: July 27, 2020

Copyright $\odot 2020$ by author(s) and Scientific Research Publishing Inc. This work is licensed under the Creative Commons Attribution International License (CC BY 4.0).

http://creativecommons.org/licenses/by/4.0/

\section{(c) (i) Open Access}

\begin{abstract}
The present study aims to test the hypothesis that a multi-component 6-week PPI programme will lead to a significant decrease in depression, anxiety, stress, and negative emotions, as well as to a significant increase of well-being, life satisfaction and positive emotions. To conduct the study, participants were recruited online and formed the experimental $(\mathrm{N}=13)$ and control $(\mathrm{N}=$ 13) groups. Each participant completed a battery of self-reported questionnaires before, after and 3-month following the completion of the programme. The self-reported questionnaires completed were the Depression, Anxiety, Stress Scale, DASS-21, the Mental Health Continuum Short Form, MHC-SF, the Scale of Positive and Negative Experience, SPANE and the Satisfaction with Life Scale, SWLS. The results support our hypothesis that PPIs could be considered as a successful alternative intervention to people with symptoms of depression, anxiety, or stress.
\end{abstract}

\section{Keywords}

Positive Psychology Interventions, Depression, Anxiety, Wellbeing

\section{Introduction}

Positive Psychology interventions (PPIs) are therapeutic methods aiming to promote positive thoughts, behaviours and emotions (Schueller, Kashdan, \& Parks, 2014; Sin \& Luybomirsky, 2009). Fordyce (1977) was the first to test whether people could feel happier if they adopt the habits of happy people. Albeit his encouraging findings, it was not until the rise of Positive Psychology in the late 1990s when PPIs started to be systematically researched. Positive Psychology sheds light on the conditions and functions that lead people, groups, 
and institutions to flourish (Gable \& Haidt, 2005). PPIs are suggested as means to facilitate flourishing and fight depression, anxiety, and stress. The efficacy of PPIs is studied in single-component (one or two positive interventions are used) and multiple-component studies (three or more activities, Hendriks, 2018).

Studies of single-component interventions highlight the interventions which appear to be more effective. For instance, there is extended literature for the effectiveness of positive interventions such as "counting blessings" (Emmons \& McCullough, 2003; Martínez-Martí, Avia, \& Hernández-Lloreda, 2010), “savoring techniques” (Hurley \& Kwon, 2012), “be your best self” (King, 2001; Layous, Nelson, \& Lyubomirsky, 2013), “gratitude letter” (Toepfer \& Walker, 2009), "goal setting" (MacLeod, Coates, \& Hetherton, 2008; Sheldon, Kasser, Smith, \& Share, 2002) or "strengthen your character strengths" (Gander, Proyer, Ruch, \& Wyss, 2012; Rashid, 2004; Wood, Linley, Maltby, Kashda, \& Hurling, 2011). These studies demonstrate the effectiveness of these interventions in enhancing life satisfaction, positive effect, happiness, and well-being among participants and in decreasing negative effect, depression, anxiety, and stress.

The combination of three or more activities leads to the formation of brief intervention programmes, which are often offered to people reporting significant emotional difficulties (Chakhssi, Kraiss, Sommers-Spijkerman, \& Bohlmeijer, 2018). Two meta-analyses reporting small, moderate, and large effects in enhancing well-being and in reducing depression have been a major point of reference for the effectiveness of PPIs (Bolier, Haverman, Westerhof, Riper, Smit, \& Bohlmeijer, 2013; Sin \& Lyubomirsky, 2009). All these findings have sprung the interest in utilizing multi-component positive interventions not only to help people flourish, but also to help them overcome the symptoms of depression, anxiety, or stress.

In Greece, a limited number of studies have been conducted for the evaluation of single-component interventions: on kindness (Symeonidou, Moraitou, Pezirkianidis, \& Stalikas, 2018), forgiveness (Zichnali, Moraitou, Pezirkianidis, \& Stalikas, 2019) and self-compassion (Karakasidou \& Stalikas, 2017). Also, a 4-week multi-component study has been conducted in school settings (Dimitropoulou \& Leontopoulou, 2017). All these studies indicate that PPIs are effective in increasing well-being, but more studies are required to further explore it.

The World Health Organization (1948) defines health as "a state of complete physical, mental and social well-being and not merely the absence of disease or infirmity". According to this definition, psychotherapy should and not only focus on the reduction of psychopathology, but also on the development of well-being. Mental health issues affect the lives of millions of people. Depression significantly impairs the daily functioning and could cause the early death of many (James et al., 2018). Anxiety is less frequently diagnosed, which may be explained by the nature of its symptoms, which are often mistaken as physical health problems and resulting in fewer people seeking psychotherapy. Anxiety hinders the person from reaching their full potential in life and could lead to de- 
pression (Leuner \& Shors, 2013). Finally, stress even if it is not considered as a psychological diagnosis, it has significant consequences on wellbeing of people. Stress emerges when the demands of the environment exceed the capacity to cope with them (Lazarus \& Folkman, 1984). To date, psychologists have effectively developed therapies for the management of such conditions (Cuijpers, Berking, Andersson, Quigley, Kleiboer, \& Dobson, 2013; Hofman \& Smits, 2008; Linde, Sigtermna, Kriston, Rücker, Meissner, \& Schneider, 2015), focusing primarily on the reduction of negative symptoms rather than on the person's flourishing (Huppert \& Whittington, 2003; Westerhof \& Keyes, 2010).

Multi-component PPI studies appear to accomplish both aims set by WHO as they are found to be highly effective in decreasing depression (Sheldon \& Lyubomirsky, 2006), anxiety (Kerr, O’Donovan, \& Pepping, 2014), stress (Flinchbaugh, Moore, Chang, \& May, 2012) and deal with major symptoms of such disorders such as sleep difficulties (Digdon \& Koble, 2011) while increasing well-being. PPIs are found to be effective even when compared with well-established therapies, such as Cognitive Behavioural Therapy in the reduction in symptoms among depressed patients and in the increase of wellbeing (Chaves, Lopez-Gomez, Hervas, \& Vazquez, 2017). Chaves and colleagues randomly allocated 96 participants to a PPI and a CBT group. The outcome measures on depression, positive and negative effect, as well as satisfaction with life indicated that both interventions were equally effective. Another important contribution of multi-components PPIs is that they could bridge the gap between demand for and offer of psychological services.

Albeit the existence of effective psychological therapies, many people with psychological difficulties do not receive any support. Firstly, there are not enough trained mental health professionals to meet the demand for psychological therapy (Butryn, Bryant, Marchionni, \& Sholevar, 2017). Moreover, people suffering from common mental health symptoms, do not recognize them, and subsequently do not seek support from mental health professionals (Andrade, Alonso, Mneimneh, Wells, Al-Hamzawi, Borges et al., 2013). In combination with the stigma still being attached to mental health issues, people may be aware of their difficulties, but hesitate to access appropriate treatment (Clement, Schauman, Graham, Maggioni, Evans-Lacko, Bezborodovs et al., 2015; Mojtabai, Olfson, \& Mechanic, 2002).

PPIs are an alternative to many people suffering from depression, anxiety, or stress as they focus on cultivating people's strengths, help them experience more positive emotions and achieve goals that lead to a more fulfilling life. The characteristics and focus of PPIs make them more attractive to people that do not recognize their symptoms as display of mental health difficulties but are aware that their lives are languishing significantly and that they are missing opportunities.

All in all, mental health difficulties, primarily depression and anxiety significantly burden people's lives. In combination with poor access to psychological 
therapy, the need for more interventions is undeniable. The promising finding from the field of Positive Psychology about the increase in well-being and reduction in psychopathology could provide a solution to this complex issue. This study aims to explore the effectiveness of a multi-component positive psychology intervention for people suffering from depression, anxiety, or stress in Greece.

\section{Present Study}

The aim of this study is to test the effectiveness of a multi-component PPI programme among Greek adults with depression, anxiety, or stress. The hypothesis is that compared to the control group, the participants in the intervention programme will demonstrate decreased levels of 1) depression, 2) anxiety, 3) stress and 4) negative emotions, as well as increased levels of 5) positive emotions, 6) satisfaction with life and 7) well-being. These improvements will remain for three months following the completion of the intervention programme. The research questions of this study are as follows:

1) Is a multi-component positive psychology intervention programme effective in decreasing levels of depression, anxiety, or stress and negative emotions compared to the control group?

2) Are the gains achieved present 3 months after the completion of the programme?

3) Is a multi-component positive psychology intervention programme effective in increasing levels of well-being, positive emotions, and satisfaction with life compared to the control group?

4) Are the gains achieved present 3 months after the completion of the programme?

\section{Method}

\subsection{Participants}

Participants were recruited from Athens, Greece via the internet. An advert for the group was posted on social media 3 months prior to the start of the intervention programme and was also sent via newsletter e-mails. Out of the one hundred and ninety-three people who completed the original questionnaire, twenty-six participated in the study forming the intervention group (13) and the control group (13) (See Figure 1). 77\% (ten) of the participants in the intervention group were women and the mean age of the group was $35.62(S D=12.626)$. For the control group, $92 \%$ were women with a mean age of $38.69(S D=9.123)$. The inclusion criteria were the presence of mild to very severe symptoms of anxiety, depression or stress as measured by the Depression Anxiety, Stress Scale (DASS). Participants who were attending another psychotherapeutic or pharmaceutical treatment were excluded from the study. In this study, we did not include any participants presenting enduring mental health difficulties during the screening interview. Table 1 outlines the demographic characteristics of the intervention and control group. 


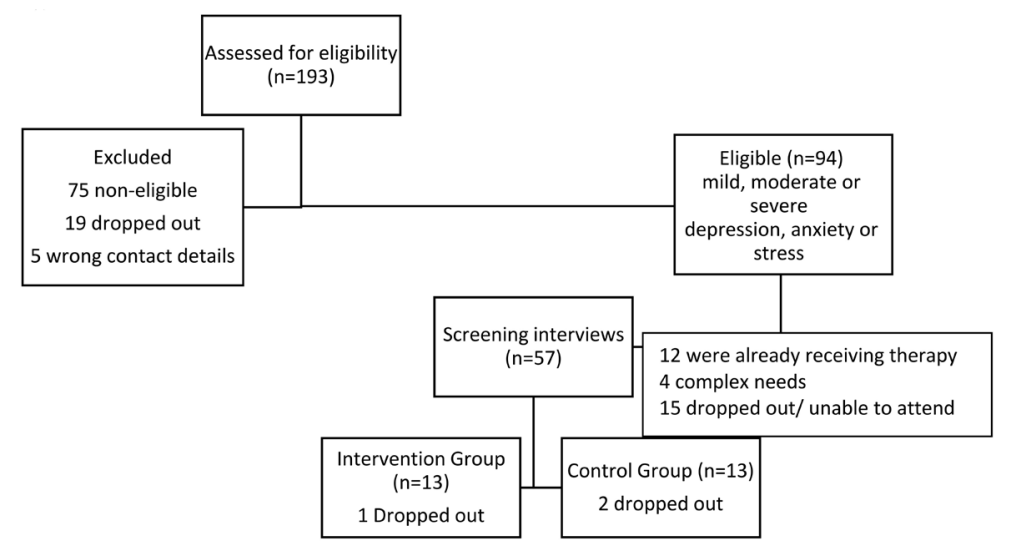

Figure 1. Selection process.

Table 1. Group demographics.

Intervention Group

\begin{tabular}{|c|c|c|}
\hline & Intervention Group & Control Group \\
\hline \multicolumn{3}{|l|}{$\operatorname{Sex} \mathrm{n}(\%)$} \\
\hline Women & $10(76.9 \%)$ & $12(92.3 \%)$ \\
\hline Men & $3(23.1 \%)$ & $1(7.7 \%)$ \\
\hline Age $\mathrm{M}(S D)$ & $35.62(12.626)$ & $38.69(9.123)$ \\
\hline \multicolumn{3}{|l|}{ Marital Status n (\%) } \\
\hline Single & $8(61.5 \%)$ & $8(61.5 \%)$ \\
\hline Married & $3(23.1 \%)$ & $4(30.8 \%)$ \\
\hline Divorced & $2(15.4 \%)$ & $1(7.7 \%)$ \\
\hline \multicolumn{3}{|l|}{ Children n (\%) } \\
\hline No children & $10(76.9 \%)$ & $8(61.5 \%)$ \\
\hline 1 child & $2(15.4 \%)$ & $1(7.7 \%)$ \\
\hline 2 children & $1(7.7 \%)$ & $3(23.1 \%)$ \\
\hline $3+$ children & $0(0 \%)$ & $1(7.7 \%)$ \\
\hline \multicolumn{3}{|l|}{ Education n (\%) } \\
\hline High school & $1(7.7 \%)$ & $1(7.7 \%)$ \\
\hline Student & $3(23.1 \%)$ & $1(7.7 \%)$ \\
\hline University graduate & $5(38.4 \%)$ & $4(30.8 \%)$ \\
\hline MSc Degree & $3(23.1 \%)$ & $7(53.8 \%)$ \\
\hline Ph.D. & $1(7.7 \%)$ & $0(0 \%)$ \\
\hline \multicolumn{3}{|l|}{ Employment n (\%) } \\
\hline Self-employed & $1(7.7 \%)$ & $3(23.1 \%)$ \\
\hline Empolyed & $7(53.8 \%)$ & $9(69.2 \%)$ \\
\hline Housekeeping & $1(7.7 \%)$ & $0(0 \%)$ \\
\hline Student & $3(23.1 \%)$ & $0(0 \%)$ \\
\hline Other & $1(7.7 \%)$ & $1(7.7 \%)$ \\
\hline
\end{tabular}




\subsection{Measures}

\section{Depression, Anxiety, Stress Scale (DASS-21)}

The DASS-21 (Lovibond \& Lovibond, 1995) is a 21-item scale which gives three scores for symptoms of depression, anxiety, and stress. It is a self-reported measure and the participant is asked to choose their answer on a 4-point Likert scale (0 "did not apply to me at all" to 3 "applied to me very much or most of the time"). The Greek standardized version of the scale was used for this study (Lyrakos, Arvaniti, Smyrnioti, \& Kostopanagiotou, 2011). In our sample, the internal consistency was $\mathrm{a}=.86$ for depression, $\mathrm{a}=.79$ for anxiety $\& \mathrm{a}=.72$ for stress.

\section{Mental Health Continuum Short Form (MHC-SF)}

The MHC-SF (Keyes et al., 2008; Ferentinos et al., 2019) assesses through 14 items the emotional, psychological and social well-being on a 6-item Likert scale, which runs from 0 ("never") to 5 ("almost always"). The scale asks the participants to consider their experience over the past four weeks and choose on a 6-point Likert scale (0 "never" to 5 "almost always) their answer. A total well-being score can be calculated by adding all the items of the scale. The scale has good psychometric properties in this study with $\mathrm{a}=.91$.

Scale of Positive and Negative Experience (SPANE)

The SPANE consists of 12 items, six relate to positive feelings and six to negative ones (Diener et al., 2010). A balance between positive and negative experiences is also calculated by subtracting the score of the negative experiences from the score of the positive ones. People choose their answer using a 5-point Likert scale (from 1 "very rarely or never" to 5 "very often or always"). The scale has been validated in the Greek population by Kyriazos, Stalikas, Prassa, \& Yotsidi (2018). In this study, the internal consistency was a $=.89$ for the positive experience and $\mathrm{a}=.83$ for the negative experience.

\section{Satisfaction with Life Scale (SWLS)}

The Greek version of the SWLS (Diener, Emmons, Larsen, \& Griffin, 1985; Stalikas \& Lakioti, 2012) was completed by the participants. SWLS assesses the global life satisfaction on a 7-point Likert scale (1 "strongly disagree" to 7 "strongly agree") with five items. The internal consistency in the present study was $\mathrm{a}=.91$.

\subsection{Procedure}

All participants were informed on the purpose of the study and gave their informed consent. The study followed the Ethics research guidelines of the Greek Psychological Society. Initially, all participants completed a battery of questionnaires, as described above, to screen those who were eligible to participate in the study. Then, those selected completed the same questionnaires at the beginning, at the end and three months after the programme completion. All questionnaires were completed online. The members of the control group were offered the opportunity to attend the intervention programme after the completion of the study. The programme was run by two experienced Psychologists-Psychotherapists. 
The material for this programme was developed by Kotsoni, Kannelakis, \& Stalikas (2020). The content was based on evidence-based positive interventions, which have been previously used with clinical populations and had been found to be effective in decreasing symptoms of depression, anxiety, or stress, as well improving wellbeing. The interventions were deriving from a wide range of topics such as gratitude, kindness, character strengths, savoring, meaning of life and positive relationships. Details for each intervention and its sequence can be found in Table 2. The programme ran for 6 weeks and each session lasted two hours. During each session, the emphasis was given in understanding a new concept of positive psychology, as well as identifies ways to incorporate it in their lives through practical exercises. In sessions, small-group exercises, discussion, and in vivo practice helped to familiarize the participants with the material presented. At the end of the programme, a relapse prevention plan was formed to help the participants further build upon their progress.

Table 2. Session by session content of the be your best you.

\begin{tabular}{|c|c|c|c|c|}
\hline Session & Topic & Psycho-educational content & Tasks \& exercises & Homework \\
\hline 1 & Introduction & $\begin{array}{l}\text { Information about the } \\
\text { intervention } \\
\text { Fostering group environment } \\
\text { Programme overview } \\
\text { Information about Positive } \\
\text { Psychology, well-being, } \\
\text { happiness \& relevant theories } \\
\text { (e.g. PERMA Seligman, 2011; } \\
\text { Diener's model, 1984) }\end{array}$ & $\begin{array}{l}\text { Warm-up exercise } \\
3 \text { good things }\end{array}$ & $\begin{array}{l}3 \text { good things } \\
\text { Complete VIA } \\
\text { Questionnaire }\end{array}$ \\
\hline 2 & $\begin{array}{l}\text { Character } \\
\text { Strengths }\end{array}$ & $\begin{array}{l}\text { Character strengths (Linley \& } \\
\text { Harrington, 2006) } \\
\text { Presentation of virtues \& } \\
\text { character strengths (Peterson \& } \\
\text { Seligman, 2004) } \\
\text { Goal setting (Lyubomirsky, 2008) }\end{array}$ & $\begin{array}{l}\text { SMART goals } \\
\text { Setting group } \\
\text { individual goals }\end{array}$ & $\begin{array}{l}\text { Use your character } \\
\text { strength in a new } \\
\text { way each day } \\
\text { Goal setting }\end{array}$ \\
\hline 3 & Savoring & $\begin{array}{l}\text { Broaden-and-build Theory } \\
\text { (Fredrickson, 2001) } \\
\text { Savoring (Bryant \& Veroff, 2007) } \\
\text { Ways to increase savoring in } \\
\text { day-to-day }\end{array}$ & $\begin{array}{l}\text { Identifying } \\
\text { activities that } \\
\text { promote happiness } \\
\text { Savoring exercise } \\
\text { List ideas to foster } \\
\text { savoring }\end{array}$ & $\begin{array}{l}\text { Identify activities } \\
\text { that increase } \\
\text { happiness } \\
\text { Practice savoring }\end{array}$ \\
\hline 4 & $\begin{array}{l}\text { Meaning } \\
\text { of Life }\end{array}$ & $\begin{array}{l}\text { Meaning of Life (Frankl, 1963; } \\
\text { McKnight \& Kashdan, 2009) }\end{array}$ & $\begin{array}{l}\text { Best possible self } \\
\text { Review goals }\end{array}$ & $\begin{array}{l}\text { Set goals based on } \\
\text { your best possible } \\
\text { self } \\
\text { Focus on achieving } \\
\text { your goals }\end{array}$ \\
\hline 5 & $\begin{array}{l}\text { Positive } \\
\text { Relationships }\end{array}$ & $\begin{array}{l}\text { Characteristics of positive } \\
\text { relationships } \\
\text { Capitalising positive news (Gable, } \\
\text { Gonzaga, \& Strachman, 2006) }\end{array}$ & $\begin{array}{l}\text { Share a positive } \\
\text { relationship } \\
\text { Gratitude Letter } \\
\text { Random acts of } \\
\text { kindness }\end{array}$ & $\begin{array}{l}\text { Communicate } \\
\text { positively } \\
\text { Do } 5 \text { random acts of } \\
\text { kindness }\end{array}$ \\
\hline 6 & $\begin{array}{l}\text { Summary } \\
\text { \& Ending }\end{array}$ & $\begin{array}{l}\text { Summary of theories, tasks \& } \\
\text { exercises }\end{array}$ & $\begin{array}{l}\text { Relapse-prevention } \\
\text { Review goals } \\
\text { Set future goals }\end{array}$ & $\mathrm{N} / \mathrm{A}$ \\
\hline
\end{tabular}




\section{Results}

No differences were observed at the baseline regarding their sociodemographic characteristics or variable measures between the control and the intervention group (Table $1 \&$ Table 3 ). The data were examined for the normality of their distribution, to decide whether parametric or non-parametric tests will be used. All data followed the normal distribution, apart from the post measure for depression in the intervention group and the follow-up measure of satisfaction with life in the control group. For the analysis of the data the programme SPSS Statistics version 25 was used.

To answer the first and third research questions, which is whether the intervention group demonstrated statistically significant differences compared to the control group, paired sample t-tests were used to examine pre and post changes for each group. The first hypothesis was fully supported. There was a statistically significant difference in the scores of the intervention group before and after the completion of the programme. The results of the t-tests were statistically significant across all the variables tested: depression $(t=3.594, p=.04)$, anxiety $(t=$ 2.708, $p=.20)$, stress $(t=4.214, p=.001)$ and negative emotions $(t=3.256, p$ $=.08)$. No statistically significant difference was observed for the post-intervention outcomes of the control group: anxiety $(t=.148, p=.885)$, stress $(t=.874, p$ $=.399)$, and negative feelings $(t=.497, p=.628)$. Wilcoxon non-parametric test was ran for the non-normally distributed data of depression $(\mathrm{Z}=-1.017, p$ $=.309$ ).

Table 3. Mean scores for outcome measures by group for pre-group (Pre), post-group (Post) and at three months follow-up (FU3).

\begin{tabular}{ccccccc}
\hline & \multicolumn{3}{c}{ Intervention Group } & \multicolumn{3}{c}{ Control Group } \\
\cline { 2 - 6 } & Pre & Post & FU3 & Pre & Post & FU3 \\
\cline { 2 - 6 } & M (SD) & M (SD) & M (SD) & M (SD) & M (SD) & M (SD) \\
\hline Depression & $8.33(4.619)$ & $5.42(4.033)$ & $5.09(3.986)$ & $8.54(4.648)$ & $7.15(4.741)$ & $9.36(4.105)$ \\
Anxiety & $5.58(3.343)$ & $2.58(1.730)$ & $3.09(2.300)$ & $6.85(4.913)$ & $6.69(3.728)$ & $8.55(5.520)$ \\
Stress & $9.67(4.075)$ & $5.42(3.679)$ & $6.00(3.000)$ & $12.08(2.985)$ & $11.54(3.479)$ & $12.55(4.886)$ \\
Wellbeing Score & $34.58(12.645)$ & $41.58(11.728)$ & $41.09(14.053)$ & $37.15(10.367)$ & $38.38(11.709)$ & $32.45(10.182)$ \\
Emotional Wellbeing & $8.33(2.741)$ & $8.75(2.006)$ & $8.36(2.420)$ & $8.77(2.386)$ & $9.54(2.665)$ & $8.27(2.573)$ \\
Social Wellbeing & $10.33(5.033)$ & $13.42(5.195)$ & $12.64(6.485)$ & $9.92(4.368)$ & $10.15(4.543)$ & $8.73(4.174)$ \\
Psychological Wellbeing & $15.92(5.600)$ & $19.42(5.869)$ & $20.09(5.839)$ & $18.46(5.254)$ & $18.69(5.851)$ & $15.45(6.235)$ \\
Positive Feelings & $17.17(4.064)$ & $20.92(4.738)$ & $20.27(3.036)$ & $17.69(4.191)$ & $17.54(4.737)$ & $17.18(5.456)$ \\
Negative Feelings & $18.50(3.606)$ & $13.58(3.919)$ & $13.64(4.056)$ & $20.46(4.841)$ & $19.85(4.375)$ & $20.64(2.730)$ \\
SWLS & $17.58(7.633)$ & $20.33(8.161)$ & $19.64(7.229)$ & $21(5.642)$ & $20.62(6.801)$ & $19.91(8.252)$ \\
\hline
\end{tabular}


Similarly, to test the third hypothesis, paired sample t-tests were used for each group. For the intervention group, we observed statistically significant increase in the levels of wellbeing $(t=-3.906, p=.002)$, positive emotions $(t=-4.486, p$ $=.001)$, and satisfaction with life $(t=-3.363, p=.006)$. No statistically significant changes were found for the control group: for wellbeing $(t=-458, p$ $=.655)$, positive emotions $(t=.122, p=.905)$ and satisfaction with life $(t=.196$, $p=.848)$.

For the second and fourth research questions, "Are the gains achieved present 3 months after the completion of the programme?" a series of t-tests comparing the post outcomes measures with the 3-months follow up were conducted. According to the findings, there were no significant difference for depression $(t$ $=.771, p=.458)$, anxiety $(t=-.631, p=.542)$, stress $(t=-.298, p=.772)$, negative emotions $(t=-.322, p=.754)$, wellbeing $(t=-.322, p=.754)$, positive emotions $(t=.159, p=.877)$ and satisfaction with life $(t=-.281, p=.785)$.

Also, for the control group, no statistically significant differences were observed for the post-intervention outcomes: anxiety $(t=-1.089, p=.302)$, stress $(t=-.798, p=.443)$, wellbeing score $(t=1.394, p=.193)$, negative feelings $(t$ $=.000, p=1.000)$, and positive feelings $(t=.309, p=.764)$. Non-parametric tests were used for depression $(Z=-1.248, p=.212)$ and satisfaction with life $(t=$ $-.268, p=.789$ ).

The changes in the outcome measures of the experimental group for the variables of depression, anxiety, stress, and negative emotions are illustrated in Figure 2. Figure 3 shows the increase in the variables of wellbeing, positive emotions, and satisfaction with life for the intervention group.

\section{Discussion}

All the hypotheses of our study were confirmed. Participants to the "Be Your Best You" programme reported statistically significant lower levels of depression, anxiety, stress, and negative emotions after the completion of the programme. There was also a significant increase in their levels of well-being, satisfaction with life and positive emotions. All the changes observed at the end of the intervention were maintained for three months following the completion of the programme. To our knowledge, this is the first multi-component study of PPIs delivered to the general population measuring both well-being and symptoms of psychopathology in Greece. All these findings enrich the existing literature regarding the effectiveness of positive psychology interventions (Chakhssi et al., 2018).

The Be Your Best You is a 6-week psycho-educational programme that gives the opportunity to the participants to learn the basic principles of Positive Psychology through practicing cognitive and behavioural interventions in vivo and during the course of the 6-week programme (see Table 2). Participants in the study present with variety of symptoms. Some of them struggling with depression, others with stress or anxiety and some with a combination of depression, anxiety, and stress. The study found that this programme can equally support these individuals to improve their symptoms and their overall well-being. 


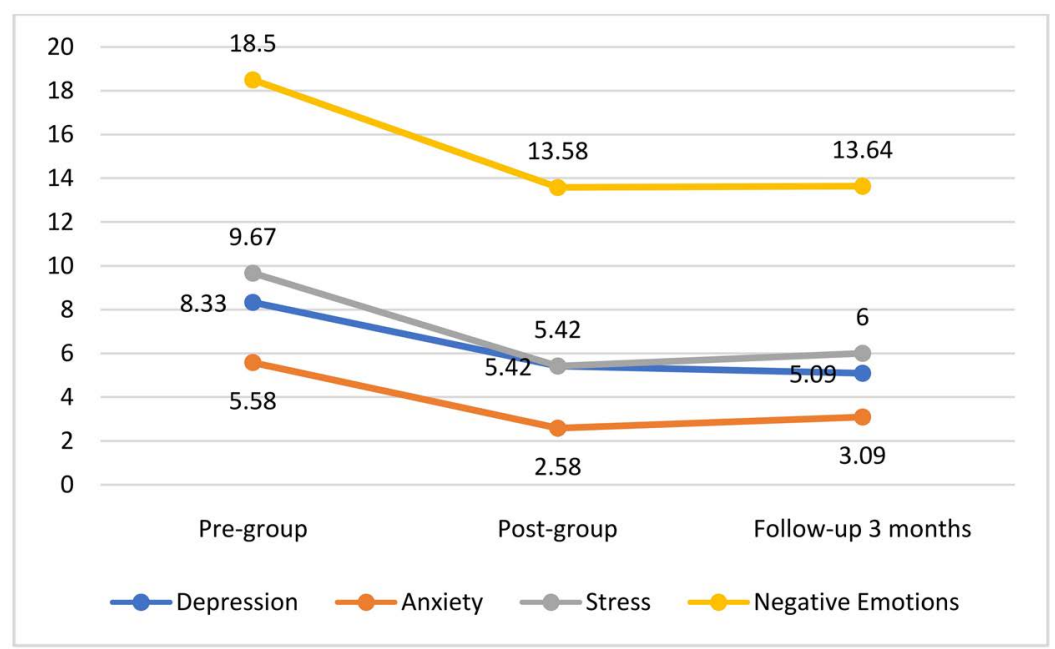

Figure 2. Depression, anxiety, stress, and negative emotion before, after and 3 months later the Be Your Best You for the experimental group.

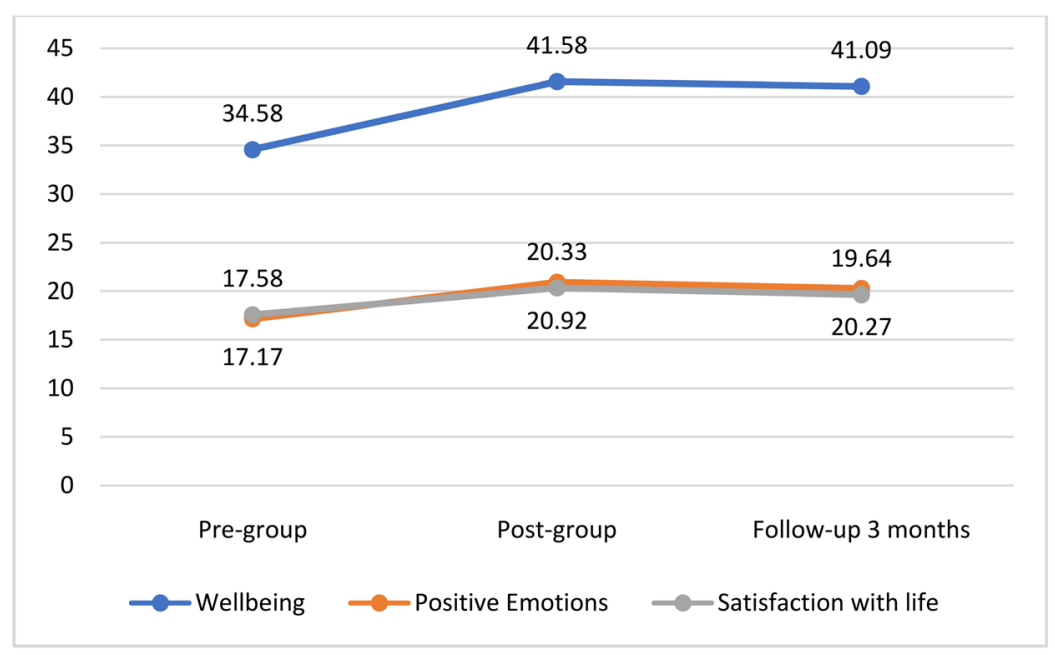

Figure 3. Wellbeing, positive emotions and satisfaction with life before, after and 3 months later the Be Your Best You for the experimental group.

Planning and delivering a transdiagnostic intervention have many benefits for the provider and the participants. Such interventions require fewer resources and are easier to be implemented. PPIs are easily disseminated and practitioners from different professions such as nurses, social workers, teachers can be trained to deliver them (Bell, Cummings, Simhai, \& Solodkin, 2019; Guzmán, Wenborn, Ledgerd, \& Orrell, 2017). As a result, more people can gain access to PPIs, not only within psychological services. More training and supervision programmes must be established to work towards this goal. Finally, the stigma attached to mental health treatment is being addressed with people coming together in a group setting. In such a group setting, participants can enrich their knowledge, practice new ideas, and observe how others respond.

At the end of the Be Your Best You, people reported increased levels of well-being. Higher levels of well-being at the end of the therapy have been found 
to act as a protection against future relapses (Grant, Munk, \& Hennig, 2018; Wood \& Joseph, 2010; Wood \& Tarrier, 2010). In combination with the decrease in depression, anxiety, or stress, the existence of higher levels of well-being can be a shield to any future relapse. With further practice, people could benefit from the upward spiral of positive emotions and use them in the future when there will need to do so. Fredrickson's broaden-and-build theory describes in detail the role of positive emotions in building and broadening physical, mental, and social resources (Fredrickson, 2013).

\subsection{Limitations and Future Directions}

The findings of this study should be considered through the lens of its methodological limitations, which should be addressed in future studies. First, the sample of our study was small and consisted of working-age adults. Future studies should aim to recruit a larger sample and potentially include adolescents and/or older adults to explore the effectiveness of PPIs across the lifespan. As far as demographics are concerned, it was observed that parents were less likely to participate compared to students. It may be the fact that increased family or work responsibilities may be an obstacle for some people to attend. Future studies can be provided online or individually and offer the flexibility required to this sub-group. Also, ethnic minorities could be considered to participate in future programmes to explore any cultural variables that may affect the outcome.

Another important factor to consider is that the selection of the individuals was made based on symptoms of depression, anxiety, or stress as measured by the DASS. DASS is designed to measure the degree of symptoms associated with these difficulties, but it is not a diagnostic tool for depression or anxiety disorders. Future studies could use more advanced self-reported tools or diagnostic interviews, so they can assess people participating in the presence of a mental health disorder according to Diagnostic and Statistical Manual of Mental Disorders (DSM-V, American Psychiatric Association, 2013). Also, although the inclusion criteria were for people presenting with mild to very severe symptoms, most of the people had moderate symptoms of depression, anxiety, or stress. At the end of the intervention, people presented with mild symptom of depression and no clinical symptoms of anxiety and stress. These changes were maintained after three months with no statistically significant increases in anxiety and stress. Future studies could include follow-up measures six or twelve months later to ensure that the gains are maintained.

Finally, the sample of this study self-selected themselves through the response to an online advert, indicating that these people were actively seeking support and had high motivation to engage. In the future, positive psychology interventions should be offered through mental health or community services as alternatives to already established therapies. Direct comparison of PPIs with other psychological therapies will strengthen the argument that PPIs are an alternative for the treatment of common psychopathology. 


\subsection{Implications}

Overall, this study has many scientific and clinical implications. In Greece, positive interventions are not yet extensively examined. Researchers in the future can further test the effectiveness of multi-component positive interventions with a larger group of people with more diverse demographics. More importantly, due to the potential of positive interventions for early intervention, populations at risk, such as carers, people with long-term health conditions, unemployed, or other sub-groups facing high levels of stress could be benefited from such intervention. Also, future studies could examine in more depth which are the components of positive interventions that contribute to the therapeutic gains.

For mental health clinicians, the Be Your Best You could provide inspiration for interventions that can be used not only in group settings, but also in individual sessions. Considering the effectiveness of the programme in the reduction of psychopathology and the increase in the well-being, mental health practitioners can yield these benefits. Finally, digital interventions could be designed to promote mental health awareness and reach out to more people.

\section{Conflicts of Interest}

The authors declare no conflicts of interest regarding the publication of this paper.

\section{References}

American Psychiatric Association (2013). Diagnostic and Statistical Manual of Mental Disorders (5th ed.). Arlington, VA: American Psychiatric Publishing. https://doi.org/10.1176/appi.books.9780890425596

Andrade, L. H., Alonso, J., Mneimneh, Z., Wells, J. E., Al-Hamzawi, A., Borges, G. et al. (2013). Barriers to Mental Health treatment: Results from the WHO World Mental Health (WMH) Surveys. Psychological Medicine, 44, 1303-1317. https://doi.org/10.1017/S0033291713001943

Bell, J. G., Cummings, K., Simhai, M., \& Solodkin, A. (2019). Positive Psychology Interventions in the Classroom for Students with Special Needs: First Book. Unpublished Thesis, Philadelphia, PA: University of Pennsylvania. https://pdfs.semanticscholar.org/c152/0b7ccac87808c13916d4d1fdc09154e0dc9a.pdf

Bolier, L., Haverman, M., Westerhof, G. J., Riper, H., Smit, F., \& Bohlmeijer, E. (2013). Positive Psychology Interventions: A Meta-Analysis of Randomized Controlled Studies. BMC Public Health, 13, Article No. 119. https://doi.org/10.1186/1471-2458-13-119

Bryant, F. B., \& Veroff, J. (2007). Savoring: A New Model of Positive Experience. Mahwah, NJ: Lawrence Erlbaum Associates.

Butryn, T., Bryant, L., Marchionni, C., \& Sholevar, F. (2017). The Shortage of Psychiatrists and Other Mental Health Providers: Causes, Current State, and Potential Solutions. International Journal of Academic Medicine, 3, 5-9. http://www.ijam-web.org/text.asp?2017/3/1/5/209851

Chakhssi, F., Kraiss, J. T., Sommers-Spijkerman, M., \& Bohlmeijer, E. T. (2018). The Effect of Positive Psychology Interventions on Well-Being and Distress in Clinical Samples with Psychiatric or Somatic Disorders: A Systematic Review and Meta-Analysis. 
BMC Psychiatry, 18, Article No. 211. https://doi.org/10.1186/s12888-018-1739-2

Chaves, C., Lopez-Gomez, I., Hervas, G., \& Vazquez, C. (2017). A Comparative Study on the Efficacy of a Positive Psychology Intervention and a Cognitive Behavioral Therapy for Clinical Depression. Cognitive Therapy and Research, 41, 417-433.

https://doi.org/10.1007/s10608-016-9778-9

Clement, S., Schauman, O., Graham, T., Maggioni, F., Evans-Lacko, S., Bezborodovs, N. et al. (2015). What Is the Impact of Mental Health-Related Stigma on Help Seeking? A Systematic Review of Quantitative and Qualitative Studies. Psychological Medicine, 45, 11-27. https://doi.org/10.1017/S0033291714000129

Cuijpers, P., Berking, M., Andersson, G., Quigley, L., Kleiboer, A., \& Dobson, K. S. (2013). A Meta-Analysis of Cognitive-Behavioural Therapy for Adult Depression, alone and in Comparison with Other Treatments. The Canadian Journal of Psychiatry, 58, 376-385. https://doi.org/10.1177/070674371305800702

Diener, E. (1984). Subjective Well-Being. Psychological Bulletin, 95, 542-575. https://doi.org/10.1037/0033-2909.95.3.542

Diener, E. D., Emmons, R. A., Larsen, R. J., \& Griffin, S. (1985). The Satisfaction with Life Scale. Journal of Personality Assessment, 49, 71-75. https://doi.org/10.1207/s15327752jpa4901_13

Diener, E., Wirtz, D., Tov, W., Kim-Prieto, C., Choi, D., Oishi, S., \& Biswas-Diener, R. (2010). New Wellbeing Measures: Short Scales to Assess Flourishing and Positive and Negative Feelings. Social Indicators Research, 97, 143-156. https://doi.org/10.1007/s11205-009-9493-y

Digdon, N., \& Koble, A. (2011). Effects of Constructive Worry, Imagery Distraction, and Gratitude Interventions on Sleep Quality: A Pilot Trial. Applied Psychology: Health and Well-Being, 3, 193-206. https://doi.org/10.1111/j.1758-0854.2011.01049.x

Dimitropoulou, C., \& Leontopoulou, S. (2017). A Positive Psychological Intervention to Promote Well-Being in a Multicultural School Setting in Greece. The European Journal of Counselling Psychology, 6, 113-137. https://doi.org/10.5964/ejcop.v6i1.141

Emmons, R. A., \& McCullough, M. E. (2003). Counting Blessings versus Burdens: An Experimental Investigation of Gratitude and Subjective Well-Being in Daily Life. Journal of Personality and Social Psychology, 84, 377-389.

https://doi.org/10.1037/0022-3514.84.2.377

Ferentinos, P., Yotsidi, V., Porichi, E., Douzenis, A., Papageorgiou, C., \& Stalikas, A. (2019). Well-Being in Patients with Affective Disorders Compared to Nonclinical Participants: A Multi-Model Evaluation of the Mental Health Continuum-Short Form. Journal of Clinical Psychology, 75, 1585-1612. https://doi.org/10.1002/jclp.22780

Flinchbaugh, C. L., Moore, E. G., Chang, Y. K., \& May, D. R. (2012). Student Well-Being Interventions: The Effects of Stress Management Techniques and Gratitude Journaling in the Management Education Classroom. Journal of Management Education, 36, 191-219. https://doi.org/10.1177/1052562911430062

Fordyce, M. W. (1977). Development of a Program to Increase Personal Happiness. Journal of Counseling Psychology, 24, 511-521. https://doi.org/10.1037/0022-0167.24.6.511

Frankl, V. E. (1963). The Philosophical Foundations of Logotherapie. Universitas, 8, 171-187.

https://search.proquest.com/openview/80d2e835fad5d10ea87501bcac89ac1f/1?pq-origs ite $=$ gscholar $\& \mathrm{cbl}=1816892$ https://doi.org/10.1159/000285538

Fredrickson, B. L. (2001). The Role of Positive Emotions in Positive Psychology. The 
Broaden-and-Build Theory of Positive Emotions. American Psychologist, 56, 218-226. https://doi.org/10.1037/0003-066X.56.3.218

Fredrickson, B. L. (2013). Positive Emotions Broaden and Build. In Advances in Experimental Social Psychology (Vol. 47, pp. 1-53). Cambridge, MA: Academic Press. https://doi.org/10.1016/B978-0-12-407236-7.00001-2

Gable, S. L., \& Haidt, J. (2005). What (and Why) Is Positive Psychology. Review of General Psychology, 9, 103-110. https://doi.org/10.1037/1089-2680.9.2.103

Gable, S. L., Gonzaga, G. C., \& Strachman, A. (2006). Will You Be There for Me When Things Go Right? Supportive Responses to Positive Event Disclosures. Journal of Personality and Social Psychology, 91, 904-917. https://doi.org/10.1037/0022-3514.91.5.904

Gander, F., Proyer, R. T., Ruch, W., \& Wyss, T. (2012). Strength-Based Positive Interventions: Further Evidence for Their Potential in Enhancing Well-Being and Alleviating Depression. Journal of Happiness Studies, 14, 1241-1259. https://doi.org/10.1007/s10902-012-9380-0

Grant, P., Munk, A. J. L., \& Hennig, J. (2018). A Positive-Psychological Intervention Reduces Acute Psychosis-Proneness. Schizophrenia Research, 199, 414-419. https://doi.org/10.1016/j.schres.2018.04.007

Guzmán, A., Wenborn, J., Ledgerd, R., \& Orrell, M. (2017). Evaluation of a Staff Training Programme Using Positive Psychology Coaching with Film and Theatre Elements in Care Homes: Views and Attitudes of Residents, Staff and Relatives. International Journal of Older People Nursing, 12, e12126. https://doi.org/10.1111/opn.12126

Hendriks, T. (2018). Positive Psychology Interventions in a Multi-Ethnic and CrossCultural Context. Doctoral Dissertation, Amsterdam: Universiteit van Amsterdam.

Hofman, S. G., \& Smits, J. A. (2008). Cognitive-Behavioral Therapy for Adult Anxiety Disorders: A Meta-Analysis of Randomized Placebo-Controlled Trials. The Journal of Clinical Psychiatry, 69, 621-632. https://doi.org/10.4088/JCP.v69n0415

Huppert, F. A., \& Whittington, J. E. (2003). Evidence for the Independence of Positive and Negative Well-Being: Implications for Quality of Life Assessment. British Journal of Health Psychology, 8, 107-122. https://doi.org/10.1348/135910703762879246

Hurley, D. B., \& Kwon, P. (2012). Results of a Study to Increase Savoring the Moment: Differential Impact on Positive and Negative Outcomes. Journal of Happiness Studies, 13, 579-588. https://doi.org/10.1007/s10902-011-9280-8

James, S. L., Abate, D., Abate, K. H., Abay, S. M., Abbafati, C., Abbasi, N., \& Abdollahpour, I. (2018). Global, Regional, and National Incidence, Prevalence, and Years Lived with Disability for 354 Diseases and Injuries for 195 Countries and Territories, 1990-2017: A Systematic Analysis for the Global Burden of Disease Study 2017. The Lancet, 392, 1789-1858. https://doi.org/10.1016/S0140-6736(18)32279-7

Karakasidou, E., \& Stalikas, A. (2017). Empowering the Battered Women: The Effectiveness of a Self-Compassion Program. Psychology, 8, 2200-2214. https://doi.org/10.4236/psych.2017.813140

Kerr, S. L., O’Donovan, A., \& Pepping, C. A. (2014). Can Gratitude and Kindness Interventions Enhance Well-Being in a Clinical Sample? Journal of Happiness Studies, 16, 17-36. https://doi.org/10.1007/s10902-013-9492-1

Keyes, C. L., Wissing, M., Potgieter, J. P., Temane, M., Kruger, A., \& van Rooy, S. (2008). Evaluation of the Mental Health Continuum-Short Form (MHC-SF) in Setswana-Speaking South Africans. Clinical Psychology \& Psychotherapy, 15, 181-192.

https://doi.org/10.1002/cpp.572 
King, L. A. (2001). The Health Benefits of Writing about Life Goals. Personality and Social Psychology Bulletin, 27, 798-807. https://doi.org/10.1177/0146167201277003

Kotsoni, A., Kanellakis, K., \& Stalikas, A. (2020). Be Your Best You: A Pilot Study of a Positive Psychology Programme for People with Depression, Anxiety or Stress in Greece. Psychology, 11, 13-29. https://doi.org/10.4236/psych.2020.111002

Kyriazos, T., Stalikas, A., Prassa, K., \& Yotsidi, V. (2018). A 3-Faced Construct Validation and a Bifactor Subjective Well-Being Model Using the Scale of Positive and Negative Experience, Greek Version. Psychology, 9, 1143-1175. https://doi.org/10.4236/psych.2018.95071

Layous, K., Nelson, S. K., \& Lyubomirsky, S. (2013). What Is the Optimal Way to Deliver a Positive Activity Intervention? The Case of Writing about One's Best Possible Selves. Journal of Happiness Studies, 14, 635-654. https://doi.org/10.1007/s10902-012-9346-2

Lazarus, R. S., \& Folkman, S. (1984). Stress, Appraisal, and Coping. New York: Springer.

Leuner, B., \& Shors, T. J. (2013). Stress, Anxiety, and Dendritic Spines: What Are the Connections? Neuroscience, 251, 108-119. https://doi.org/10.1016/j.neuroscience.2012.04.021

Linde, K., Sigterman, K., Kriston, L., Rücker, G., Jamil, S., Meissner, K., \& Schneider, A. (2015). Effectiveness of Psychological Treatments for Depressive Disorders in Primary Care: Systematic Review and Meta-Analysis. The Annals of Family Medicine, 13, 56-68. https://doi.org/10.1370/afm.1719

Linley, P., \& Harrington, S. (2006). Strengths Coaching: A Potential-Guided Approach to Coaching Psychology. International Coaching Psychology Review, 1, 37-46.

Lovibond, P. F., \& Lovibond, S. H. (1995). The Structure of Negative Emotional States: Comparison of the Depression Anxiety Stress Scales (DASS) with the Beck Depression and Anxiety Inventories. Behaviour Research and Therapy, 33, 335-343. https://doi.org/10.1016/0005-7967(94)00075-U

Lyrakos, G. N., Arvaniti, C., Smyrnioti, M., \& Kostopanagiotou, G. (2011). Translation and Validation Study of the Depression Anxiety Stress Scale in the Greek General Population and in a Psychiatric Patient's Sample. European Psychiatry, 26, 1731. https://doi.org/10.1016/S0924-9338(11)73435-6

Lyubomirsky, S. (2008). Happiness Activity No. 10: Committing to Your Goals. In S. Lyubomirsky (Ed.), The How of Happiness: A Scientific Approach to Getting the Life You Want (pp. 494-545). New York: The Penguin Press.

MacLeod, A. K., Coates, E. \& Hetherton, J. (2008). Increasing Well-Being through Teaching Goal-Setting and Planning Skills: Results of a Brief Intervention. Journal of Happiness Studies, 9, 185-196. https://doi.org/10.1007/s10902-007-9057-2

Martínez-Martí, M. L., Avia, M. D., \& Hernández-Lloreda, M. J. (2010). The Effects of Counting Blessings on Subjective Well-Being: A Gratitude Intervention in a Spanish Sample. The Spanish Journal of Psychology, 13, 886-896. https://doi.org/10.1017/S1138741600002535

McKnight, P. E., \& Kashdan, T. B. (2009). Purpose in Life as a System That Creates and Sustains Health and Well-Being: An Integrative, Testable Theory. Review of General Psychology, 13, 242-251. https://doi.org/10.1037/a0017152

Mojtabai, R., Olfson, M., \& Mechanic, D. (2002). Perceived Need and Help-Seeking in Adults with Mood, Anxiety, or Substance Use Disorders. Archives of General Psychiatry, 59, 77-84. https://doi.org/10.1001/archpsyc.59.1.77

Peterson, C., \& Seligman, P. (2004). Character Strengths and Virtues: A Handbook and Classification (Vol. 1, pp. 553-568). Washington DC: American Psychological Association. 
Rashid, T. (2004). Enhancing Strengths through the Teaching of Positive Psychology. Doctoral Dissertation, Florham Park: Fairleigh Dickinson University.

Schueller, S., Kashdan, T., \& Parks, A. (2014). Synthesizing Positive Psychological Interventions: Suggestions for Conducting and Interpreting Meta-Analyses. International Journal of Wellbeing, 4, 91-98.

Seligman, M. E. P. (2011). Flourish. New York: Simon \& Schuster.

Sheldon, K. M., \& Lyubomirsky, S. (2006). How to Increase and Sustain Positive Emotion: The Effects of Expressing Gratitude and Visualizing Best Possible Selves. The Journal of Positive Psychology, 1, 73-82. https://doi.org/10.1080/17439760500510676

Sheldon, K. M., Kasser, T., Smith, K., \& Share, T. (2002). Personal Goals and Psychological Growth: Testing an Intervention to Enhance Goal Attainment and Personality Integration. Journal of Personality, 70, 5-31. https://doi.org/10.1111/1467-6494.00176

Sin, N. L. \& Lyubomirsky, S. (2009). Enhancing Well-Being and Alleviating Depressive Symptoms with Positive Psychology Interventions: A Practice-Friendly Meta-Analysis. Journal of Clinical Psychology, 65, 467-487. https://doi.org/10.1002/jclp.20593

Stalikas, A., \& Lakioti, A. (2012). Satisfaction with Life Scale (SWLS). In A. Stalikas, S. Triliva, \& P. Roussi (Eds.), Psychometric Instruments in Greece (2nd ed., p. 752). Athens: Pedio.

Symeonidou, D., Moraitou, D., Pezirkianidis, C., \& Stalikas, A. (2018). Promoting Subjective Wellbeing through a Kindness Intervention. Hellenic Journal of Psychology, 16, 1-21.

Toepfer, S. M., \& Walker, K. (2009). Letters of Gratitude: Improving Well-Being through Expressive Writing. Journal of Writing Research, 1, 181-198. https://doi.org/10.17239/jowr-2009.01.03.1

Westerhof, G. J., \& Keyes, C. L. (2010). Mental Illness and Mental Health: The Two Continua Model across the Lifespan. Journal of Adult Development, 17, 110-119. https://doi.org/10.1007/s10804-009-9082-y

Wood, A. M., \& Joseph, S. (2010). The Absence of Positive Psychological (Eudemonic) Well-Being as a Risk Factor for Depression: A Ten-Year Cohort Study. Journal of Affective Disorders, 122, 213-217. https://doi.org/10.1016/j.jad.2009.06.032

Wood, A. M., \& Tarrier, N. (2010). Positive Clinical Psychology: A New Vision and Strategy for Integrated Research and Practice. Clinical Psychology Review, 30, 819-829. https://doi.org/10.1016/j.cpr.2010.06.003

Wood, A. M., Linley, P. A., Maltby, J., Kashdan, T. B., \& Hurling, R. (2011). Using Personal and Psychological Strengths Leads to Increases in Well-Being over Time: A Longitudinal Study and the Development of the Strengths Use Questionnaire. Personality and Individual Differences, 50, 15-19. https://doi.org/10.1016/j.paid.2010.08.004

World Health Organization (1948). World Health Organization Constitution. Basic Documents, 1, 22.

Zichnali, O., Moraitou, D., Pezirkianidis, C., \& Stalikas, A. (2019). Examining the Effectiveness of Two Types of Forgiveness Intervention to Enhance Well-Being in Adults from Young to Older Adulthood. OBM Geriatrics, 3, 29.

https://doi.org/10.21926/obm.geriatr.1902044 